\title{
The Effect of Extended Injection of Subcutaneous Heparin on Pain Intensity and Bruising Incidence
}

\author{
Mostafa Ahmadi ${ }^{1}$, Raheleh Ahmadi ${ }^{2}$, Zoleykha Saadati ${ }^{1}$, Omid Mehrpour ${ }^{3,4}$
}

\author{
${ }^{1}$ Department of Cardiology, Qaem Hospital, Mashhad University of Medical Sciences, Mashhad, Iran \\ ${ }^{2}$ Department of Gynecology, Sabzevar University of Medical Sciences, Sabzevar, Iran \\ ${ }^{3}$ Atherosclerosis and Coronary Artery Research Centre, Birjand University of Medical Science, Birjand, Iran \\ ${ }^{4}$ Medical Toxicology and Drug Abuse Research Center (MTDRC), Birjand University of Medical Science, Birjand, \\ Iran
}

\section{Type of article: Original}

\begin{abstract}
Background: Reducing patients' pain is one of the main goals of providing clinical services, which requires nursing skill. As a simple technique, increasing the duration of subcutaneous heparin injection may affect the intensity of pain and bruising.

Objective: The aim of this study was to assess the effect of increasing the heparin injection time on pain intensity and bruising associated with subcutaneous injection.

Methods: The present quasi-experimental study consisted of 86 patients, admitted to our hospital, who were treated with subcutaneous heparin injection. A McGill pain intensity questionnaire was used to measure pain severity in a purposive sampling. All of the subjects received subcutaneous heparin twice for 10 seconds. They also were injected twice with heparin infusion, although it was for 30 seconds this time. The interval between the two injections was $24 \mathrm{~h}$, and the intensity of the pain was measured after each injection. The Pearson correlation coefficient was measured, and analysis of variance (ANOVA) and the t-test were used to analyze the data.

Results: Eighty patients received heparin. The body mass indexes were reported as $52(60 \%)$ and $34(40 \%)$ for subjects within the age range of 18.5-24.9 and 25-29.9, respectively. Regarding the mean of pain intensity, there was a significant difference between the 10 and $30 \mathrm{~s}$ injections $(\mathrm{p}<0.05)$. Additionally, there was a significant difference in bruising rates between the two methods 48 and $72 \mathrm{~h}$ after injection $(\mathrm{p}<0.05)$. The ANOVA test showed a significant association between gender and bruising $(\mathrm{p}=0.001)$.

Conclusion: According to the results, by elevating the duration of heparin injection, the severity of pain was reduced, and, therefore, the patients felt more comfortable.

Trial Registration: The trial was registered at the Thai Clinical Trials Registry (TCTR) with the TCTR identification of TCTR20160221001.

Funding: This research was supported by the research cluster grant (88186-25/01/89) from Mashhad University of Medical Sciences, Mashhad, Iran. The authors received no financial support for the authorship and/or publication of this article.
\end{abstract}

Keywords: Extended injection time; Heparin; Pain intensity; Bruising

\section{Introduction}

Reduction of patients' pain is one of the main goals in clinical services, and it requires nursing skills. Many studies have considered "pain as the fifth vital sign" due to the importance of pain management and patients' comfort and convenience (1-4). Although pain is one of the most treatable disease symptoms, its relief/reduction is still considered as one of the greatest failures of modern medicine (5). The knowledge related to pain mechanisms has increased rapidly, particularly in the last 30 years (6). Pain and bruising are two major concerns regarding injection for many hospitalized patients. Hence, particular attention should be paid to finding solutions for alleviating

\section{Corresponding author:}

Zoleykha Saadati, Department of Cardiology, Qaem Hospital, Mashhad University of Medical Sciences, Mashhad, Iran. Email: saadatiz1@mums.ac.ir

Received: November 04, 2015, Accepted: April 02, 2016, Published: July 2016

iThenticate screening: March 30, 2016, English editing: May 17, 2016, Quality control: June 20, 2016

(C) 2016 The Authors. This is an open access article under the terms of the Creative Commons Attribution-NonCommercialNoDerivs License, which permits use and distribution in any medium, provided the original work is properly cited, the use is non-commercial and no modifications or adaptations are made. 
patients' fear and concerns. Studies on injection techniques could increase awareness, knowledge, and skills related to subcutaneous injections, and, consequently, reduce pain and bruising. Subcutaneous injections are mostly associated with pain and bruising (7-9). Heparin is used for the treatment of venous thromboembolism in patients with medical illness, coronary, and neurological disorders $(10,11)$. It also is used as an anticoagulant for the prevention and treatment of blood clots during dialysis and after surgery. Heparin is clinically used for the treatment of venous and mural thrombosis and pulmonary embolism for patients with unstable angina. The anticoagulant effects of heparin include activation of antithrombin III, inhibition of platelet aggregation, and additional antithrombin III-independent inhibitors $(12,13)$. Moreover, it is used to prevent acute thrombosis after coronary thrombolysis and to alleviate the bruising and pain caused by the injection (14). Several authors have mentioned the role of low-molecular-weight heparin in the reduction of bruising (15-17). Unfractionated heparin is a heterogeneous mixture of sulfated polysaccharides, ranging in molecular weight from 3,000 to 40,000 Daltons. Subcutaneous heparin injection must be performed in certain dosages according to the patient's medical condition, weight, and response to treatment method. Due to insufficient research in this field and the importance of pain/bruise alleviation after injection, this study aimed to study the effect of heparin on pain intensity and bruising associated with subcutaneous injection.

\section{Material and Methods}

\subsection{Trial design and participants}

This clinical trial was conducted from April 14, 2010 to October 19, 2011. The study population consisted of all patients who were admitted to the Cardiology Department at Ghaem Hospital and who received subcutaneous heparin injection. In this quasi-experimental study, the independent variable (subcutaneous injection duration) was manipulated, and the dependent variables (pain severity and bruising) were assessed.

\subsection{Selection criteria}

The patients who met the following criteria were included in the study: 1) subcutaneous heparin prescription $(5,000$ units per $1 \mathrm{~mL}$, every $12 \mathrm{~h}$ ) by a physician, 2) full consciousness, 3) lack of pain and disease (such as blood coagulation, hepatic impairment, renal failure, nervous and sensory impairment in the injection site, spinal injury, diabetes, and vascular disorders), 4) no smoking or drug abuse, 5) no use of warfarin or phenobarbital, 6) no painrelief interventions or use of analgesic medicines, 7) no redness, swelling, and bruising at the injection site, 8) age range of 40-69, 9) controlled partial thromboplastin time (PTT), 10) BMI of 18.5-29.9, and 11) willingness to participate in the study.

\subsection{Outcomes and Interventions}

The outcomes of our analyses were the pain intensity immediately after injection and the bruising size at 48 and $72 \mathrm{~h}$ after injections with 10 and 30-s durations in the same patients. The subjects were selected using the purposive sampling technique. After the researchers' visit to the cardiology and coronary care (CCU) units, the patients who met the inclusion criteria were selected.

\subsection{Sample size, randomization and blinding}

The sample size was calculated as 86 subjects based on the results of previous studies (18-20) by assuming the confidence level and test power as 95 and $80 \%$, respectively. Each patient was first considered as a control subject. The choice of patient's hand (right or left) for the first injection was random, and all of the injections were performed by one single researcher. All the participants received heparin twice for $10 \mathrm{~s}$. They also were injected twice with heparin infusion for $30 \mathrm{~s}$. The interval between the two injections was $24 \mathrm{~h}$, and the intensity of pain was measured after each injection. The Pearson correlation coefficient was measured between them.

\subsection{Statistical methods}

The content validity method was used to determine the validity of the data collection tools. The McGill pain questionnaire was used as an 11-point numeric rating scale of pain intensity (range: 0-10). SPSS v16 was used for the statistical analysis, while chi-squared test, ANOVA and the t-test were conducted to analyze the data that were obtained. A p-value less than 0.05 was considered statistically significant in all measurements.

\subsection{Research ethics}

Clearance to conduct this study was provided by the Ethics Committee, Mashhad University of Medical Sciences. Informed consent forms were obtained from the hospital authorities and patients who participated in this study. The participants were ensured about the confidentiality of the information that was gathered. The medical files of all 
participants who received subcutaneous heparin were collected, and the aims of the study were explained to the subjects.

\section{Results}

Eighty patients were injected with heparin in order to assess the pain intensity and bruising. Six (7\%), 18 (21\%), 36 (42\%), and $26(30 \%)$ patients were within the age range of 40-49, 50-59, 60-69, and 70-79, respectively; the mean age was 67.5 . Thirty-eight (44\%) patients were females, and 48 patients $(56 \%)$ were males. The BMI values were found to be 18.5-24.9 and 25-29.9 for $52(60 \%)$ and $34(40 \%)$ subjects, respectively. Most of the patients experienced pain with an intensity of 2, during the 10-s injection, while no pain was reported for the injection duration of $30 \mathrm{~s}$. The intensity of pain was significantly different $(\mathrm{p}=0.005)$ between the 10 -s $(2.79 \pm 1.42)$ and 30 -s $(0.77 \pm 0.910)$ injections (Table 1$)$. The comparison of pain intensity among males and females did not show any significant differences $(\mathrm{p}>0.05)$. The pain intensity was $2.25 \pm 1.19$ and $0.54 \pm 0.13$ for 10 -s and 30-s injection durations among men, respectively. Regarding females, the intensity of pain was $2.47 \pm 1.22$ and $1.05 \pm 0.97$ for 10 $\mathrm{s}$ and 30-s injection durations, respectively. The ANOVA test showed no association between BMI and the intensity of pain $(p>0.05)$. However, there was a significant association between the duration of the injection and the size of the bruising after 48 and $72 \mathrm{~h}$ of injection $(\mathrm{p}=0.05)$. The t-test indicated that there was a significant difference between bruising rates associated with the two methods of injection $(\mathrm{p}=0.001, \mathrm{t}=1.2 ;$ and $\mathrm{p}=0.000, \mathrm{t}=5.9$, respectively) (Table 2). The incidence of bruising among females was higher than among males $48 \mathrm{~h}$ after the injection; also, the highest bruising rate after $48 \mathrm{~h}$ was observed among females with 10-s injections. The ANOVA test indicated that there was a significant association between gender and the bruising of the two injections $(\mathrm{p}=$ 0.03). Moreover, there was a significant difference between gender and bruising rate $(\mathrm{p}=0.001)$. Additionally, a significant difference was observed in the evaluation of the relationship between gender and bruising rate after $72 \mathrm{~h}$, $(\mathrm{p}=0.001)($ Table 3$)$.

Table 1. Frequency distribution of pain intensity after 10-s and 30-s heparin injections

\begin{tabular}{|l|l|l|}
\hline \multirow{2}{*}{ Pain intensity (0 - 10) } & \multicolumn{2}{|l|}{ Injection duration } \\
\cline { 2 - 3 } & 10 seconds & 30 seconds \\
\hline 0 & $14(16 \%)$ & $42(49 \%)$ \\
\hline 1 & $2(2 \%)$ & $28(33 \%)$ \\
\hline 2 & $28(33 \%)$ & $10(11 \%)$ \\
\hline 3 & $12(14 \%)$ & $6(7 \%)$ \\
\hline 4 & $24(28 \%)$ & $0(0 \%)$ \\
\hline 5 & $6(7 \%)$ & $0(0 \%)$ \\
\hline Total & $86(100 \%)$ & $86(100 \%)$ \\
\hline Mean & 2.79 & 0.77 \\
\hline Standard deviation & 1.42 & 0.9 \\
\hline
\end{tabular}

Table 2. Distribution of the bruised sites associated with the two injection methods (10-s and 30-s injections) 48 and 72 hours after the injections

\begin{tabular}{|c|c|c|c|c|}
\hline \multirow{3}{*}{$\begin{array}{l}\text { Bruised area } \\
\left(\mathrm{mm}^{2}\right)\end{array}$} & \multicolumn{4}{|c|}{ Injection duration } \\
\hline & \multicolumn{2}{|c|}{10 seconds } & \multicolumn{2}{|l|}{30 seconds } \\
\hline & $\begin{array}{l}48 \text { hours after } \\
\text { injection }\end{array}$ & $\begin{array}{l}72 \text { hours after } \\
\text { injection }\end{array}$ & $\begin{array}{l}48 \text { hours after } \\
\text { injection }\end{array}$ & $\begin{array}{l}72 \text { hours after } \\
\text { injection }\end{array}$ \\
\hline $0-1.99$ & 26 & 32 & 37 & 42 \\
\hline $2-4$ & 28 & 30 & 31 & 25 \\
\hline $4-6$ & 20 & 17 & 13 & 15 \\
\hline$>6$ & 12 & 9 & 7 & 4 \\
\hline Mean & 8.34 & 6.82 & 4.29 & 3.46 \\
\hline $\mathrm{SD}$ & 8.94 & 8.03 & 7.86 & 6.88 \\
\hline Incidence rate & 67.4 & 55.8 & 41 & 39.5 \\
\hline
\end{tabular}


Table 3. Mean of bruising size associated with 10 -s and 30-s injections after 48 and 72 hours with regard to gender

\begin{tabular}{|c|c|c|c|c|c|c|c|c|}
\hline \multirow{4}{*}{$\begin{array}{l}\text { Statistics } \\
\text { regarding the } \\
\text { bruised area }\end{array}$} & \multicolumn{8}{|l|}{ Gender } \\
\hline & \multicolumn{4}{|c|}{ Male } & \multicolumn{4}{|c|}{ Female } \\
\hline & \multicolumn{2}{|c|}{$\begin{array}{l}48 \text { hours after the } \\
\text { injection }\end{array}$} & \multicolumn{2}{|c|}{$\begin{array}{l}72 \text { hours after the } \\
\text { injection }\end{array}$} & \multicolumn{2}{|c|}{$\begin{array}{l}48 \text { hours after the } \\
\text { injection }\end{array}$} & \multicolumn{2}{|c|}{$\begin{array}{l}72 \text { hours after the } \\
\text { injection }\end{array}$} \\
\hline & $\begin{array}{l}10 \\
\text { seconds }\end{array}$ & $\begin{array}{l}30 \\
\text { seconds }\end{array}$ & $\begin{array}{l}10 \\
\text { seconds }\end{array}$ & $\begin{array}{l}30 \\
\text { seconds }\end{array}$ & $\begin{array}{l}10 \\
\text { seconds }\end{array}$ & $\begin{array}{l}30 \\
\text { seconds }\end{array}$ & $\begin{array}{l}10 \\
\text { seconds }\end{array}$ & $\begin{array}{l}30 \\
\text { seconds }\end{array}$ \\
\hline Mean & 2.2 & 0.83 & 2.02 & 0.46 & 4.5 & 3.5 & 5.1 & 2.9 \\
\hline SD & 2.6 & 2.02 & 2.9 & 1.02 & 2.4 & 5.5 & 2.8 & 1.3 \\
\hline Incidence rate & 45.8 & 8.3 & 37.5 & 4.1 & 94.7 & 89.4 & 89.4 & 73.6 \\
\hline
\end{tabular}

\section{Discussion}

The aim of this experiment was to explore the effects of two different injection techniques on pain and bruising associated with the subcutaneous injection of heparin. The findings indicated that the mean and standard deviation of the 10-s injection were higher than those of the 30-s injection method. It seems that the pain intensity of the 30-s injection was lower than that of the 10-s heparin injection. Chan studied the effect of injection duration on pain intensity and bruising associated with subcutaneous heparin (18). Correspondingly, he showed that pain intensity in the 30-s method was lower than in the 10-s heparin injection; Chan et al. reported a significant difference between pain intensity and injection duration. In the current study, a significant association was observed between pain intensity and gender. In fact, the effect of injection duration on pain severity was stronger for females than for males. Similarly, Kuzu et al. (7) reported a significant association between pain intensity and gender. They also investigated the effect of cold on reducing the pain and bruising associated with subcutaneous injection of heparin. Zaybak et al. (19) studied the effect of the duration of subcutaneous heparin injection on bruising and pain severity. They concluded that injection duration affected bruising and pain, followed by subcutaneous administration of heparin. Similarly, our findings showed that there was a significant relationship between bruising rate and duration of injection; in the 30-s injections, the size of the bruising was smaller than that of the 10-s injection after 48 and 72 h. Chan (18) evaluated two subcutaneous heparin injection techniques to determine the effects of different injection duration (10-s and 30-s injections) on pain intensity and bruising. The results indicated that the longer injection duration ( $30 \mathrm{~s})$ led to significantly less intense pain and smaller bruises. In the current study, the mean size of bruising in females was larger than in males $48 \mathrm{~h}$ after the injection in both methods (10 s and $30 \mathrm{~s}$ injections); there was a significant correlation between the mean size of the bruised site and gender 48 and $72 \mathrm{~h}$ after the injections. This indicated that the longer duration of heparin injection (30 s) was more effective for females in reducing pain and bruising. Our results reconfirmed the findings of Balci Akpinar et al.'s (20) study on the effect of injection duration on the bruising associated with subcutaneous heparin. They reported that significantly smaller and fewer bruises were observed in the 30 -s injections than for the 10 -s injections.

\section{Conclusions}

Our data showed that extending the duration of injection in patients receiving subcutaneous heparin decreased the intensity of pain, irrespective of gender or BMI. However, elongation of injection time was more effective in minimizing the bruising size in women than it was for men. All in all, application of the simple and free-of-charge technique of slow injection with subcutaneous heparin can result in significantly less pain and, hence, more patient comfort. Similar techniques might be applicable to other subcutaneous injections and will need further studies.

\section{Acknowledgments:}

This study was done as a project submitted to the research cluster, Mashhad University of Medical Sciences, Mashhad, Iran. The authors are grateful for the help and cooperation provided by the nursing and administrative staff in the Cardiology Department of Ghaem Hospital, and we sincerely appreciate all the patients who participated in this study.

\section{Trial Registration:}

The trial was registered at the Thai Clinical Trials Registry (TCTR) with the TCTR identification of TCTR20160221001

\section{Funding:}

This research was supported by the research cluster grant (88186-25/01/89) from Mashhad University of Medical Sciences, Mashhad, Iran. The authors received no financial support for the authorship and/or publication of this article. 


\section{Conflict of Interest:}

There is no conflict of interest to be declared.

\section{Authors' contributions:}

All authors contributed to this project and article equally. All authors read and approved the final manuscript.

\section{References:}

1) Lee HS. Physical Diagnosis 101: A Lesson From the First Year of Medical School. ASA. 2004; 68(11): 37. doi: $10.1016 / j . s n a .2003 .10 .008$.

2) Lynch M. Pain as the fifth vital sign. J Gen Intern Med. 2001; 24(2): 85-94. doi: 10.1111/j.15251497.2006.00415. PMCID: 1924634.

3) Yuen T, Irwin M. The'fifth vital sign'. HKMJ. 2005; 11(3): 145-6. PMID: 15951577.

4) Dorothy'Dale'M M, Torma L, Byock I, Norris K. Speaking the language of pain. AJN. 2001; 101(2): 44-50. PMID: 11227229.

5) Parfitt K, Martindale W. The complete drug reference. Pharmaceutical Press, London. 1999; 31: 51.

6) Fowler-Kerry S, Lander JR. Management of injection pain in children. Pain. 1987; 30(2): 169-75. doi: 10.1016/0304-3959(87)91072-4. PMID: 3670868.

7) Venketasubramanian N, Chua HC. Subcutaneous low molecular weight heparin in place of heparin infusion during warfarin dose optimisation in cerebral ischaemia. Clin Neurol Neurosurg. 1998; 100(3): 193-5. doi: 10.1016/S0303-8467(98)00039-0. PMID: 9822840.

8) Ross S, Soltes D. Heparin and haematoma: does ice make a difference? J Adv Nurs. 1995; 21(3): 434-9. doi: 10.1111/j.1365-2648.1995.tb02724. PMID: 7745195.

9) Kuzu N, Ucar H. The effect of cold on the occurrence of bruising, haematoma and pain at the injection site in subcutaneous low molecular weight heparin. Int J Nurs Stud. 2001; 38(1): 51-9. doi: 10.1016/S00207489(00)00061-4. PMID: 11137723.

10) Bergqvist D. Enoxaparin: A pharmacoeconomic review of its use in the prevention and treatment of venous thromboembolism and in acute coronary syndromes. Pharmacoeconomics. 2002; 20(4): 225-43. doi: 10.2165/00019053-200220040-00002. PMID: 11950380.

11) Warner GT, Perry CM. Enoxaparin: in the prevention of venous thromboembolism in medical patients. Am J Cardiovasc Drugs. 2001; 1(6): 477-81; discussion 83-4. PMID: 14728009.

12) CM J. Mechanism of heparin action. Baillieres Clin Haematol. 1990; 3(3): 483-504. PMID: 22566220.

13) Machovich R. Mechanism of action of heparin through thrombin on blood coagulation. Biochim Biophys Acta. 1975; 412(1): 13-7. doi: 10.1016/0005-2795(75)90334-7. PMID: 1191673.

14) Hirsh J, Anand SS, Halperin JL, Fuster V. Mechanism of action and pharmacology of unfractionated heparin. Arterioscler Thromb Vasc Biol. 2001; 21(7): 1094-6. doi: 10.1161/hq0701.093686. PMID: 11451734.

15) Hull RD, Pineo GF, Stein PD, Mah AF, MacIsaac SM, Dahl OE, et al. Timing of initial administration of low-molecular-weight heparin prophylaxis against deep vein thrombosis in patients following elective hip arthroplasty: a systematic review. Archives of Internal Medicine. 2001; 161(16): 1952-60. doi: 10.1001/archinte.161.16.1952. PMID: 11525697.

16) Palese A, Aidone E, Dante A, Pea F. Occurrence and extent of Bruising according to duration of administration of subcutaneous Low-Molecular-Weight Heparin: a quasi-experimental case-crossover study. J Cardiovasc Nurs. 2013; 28(5): 473-82. doi: 10.1097/JCN.0b013e3182578b87. PMID: 22760174.

17) Santamaria A, Romani J, Souto J, Lopez A, Mateo J, Fontcuberta J. Skin necrosis at the injection site induced by low-molecular-weight heparin: case report and review. Dermatology. 1998; 196(2): 264-5. doi: 10.1159/000017889. PMID: 9568422.

18) Chan $\mathrm{H}$. Effects of injection duration on site - pain intensity and bruising associated with subcutaneous heparin. J Adv Nurs. 2001; 35(6): 882-92. doi: 10.1046/j.1365-2648.2001.01925. PMID: 11555036.

19) Zaybak A, Khorshid L. A study on the effect of the duration of subcutaneous heparin injection on bruising and pain. J Clin Nurs. 2008; 17(3): 378-85. doi: 10.1111/j.1365-2702.2006.01933. PMID: 17931375.

20) Akpinar RB, Celebioglu A. Effect of injection duration on bruising associated with subcutaneous heparin: a quasi-experimental within-subject design. Int $\mathrm{J}$ Nurs Stud. 2008; 45(6): 812-7. doi: 10.1016/j.jinurstu.2007.02.005. PMID: 17399715. 